\title{
Desain Konstruksi Press Tool Sebagai Alat Bending Bentuk V Dengan Garis Bending Max. 300mm
}

\author{
Muhammad Arsyad Suyuti ${ }^{1^{*}}$, Muhammad Iswar ${ }^{2}$, Rusdi Nur $^{3}$ dan Erniyanti ${ }^{4}$ \\ 1,2,3,4 Jurusan Teknik Mesin, Politeknik Negeri Ujung Pandang, Makassar 90245, Indonesia \\ *muhammadarsyadsuyuti@poliupg.ac.id
}

\begin{abstract}
Nowadays, the process of metal forming in the machining industry and welding workshop is developing very rapidly especially in the plate bending process. The bending process is the formation of metals which generally use plates or rods of both ferrous and non-ferrous metal materials by bending, which in the bending process will cause stretching or stretching on the neutral plane axis along the bending area and produce a straight bend line. The use of appropriate technology machines has been widely used to increase productivity, efficiency, and effectiveness in the production process for community businesses, especially those in the regions. One of the appropriate technologies that might be applied in the bending process is a hydraulic jack press that is equipped with a press tool. Press tool is one type of product forming, cutting and bending tools from the basic material of sheet plates whose operations are using a press tool. The results of the design of press tool bending tool $V$ have a length of $300 \mathrm{~mm}$ bending line, $33 \mathrm{~mm}$ bending width, $110 \mathrm{~mm}$ spring height, free step distance of 19 $\mathrm{mm}$. The punch angle used is $85 \square$ with the punch radius used is $1.5 \mathrm{~mm}$ while the die angle is $85 \square$. The selected punch and die material is Steel AISI 1045 HV HR.
\end{abstract}

Keywords: V-Bending; Press tool; Punch; Dies

\begin{abstract}
Abstrak: Dewasa ini proses pembentukan logam (metal forming) pada industri permesinan dan bengkel las berkembang sangat pesat khususnya pada proses bending pelat. Proses bending merupakan pembentukan logam yang umumnya mengunakan lembaran pelat atau batang baik dari bahan logam ferro maupun logam non ferro dengan cara dibending, yang mana dalam proses bending akan menyebabkan terjadinya pemuluran atau peregangan pada sumbu bidang netral sepanjang daerah tekukan dan menghasilkan garis tekuk yang lurus. Penggunaan mesin-mesin berteknologi tepat guna telah banyak digunakan untuk meningkatkan produktivitas, efisiensi, dan efektivitas dalam proses produksi bagi usaha-usaha masyarakat khususnya yang ada di daerah. Salah satu teknologi tepat guna yang memungkinkan diterapkan dalam proses bending adalah alat press dongkrak hidrolik yang dilengkapi dengan press tool. Press tool adalah salah satu jenis alat bantu pembentukan, pemotongan dan bending produk dari bahan dasar lembaran pelat yang operasinya menggunakan alat/mesin press. Hasil desain press tool alat bending V berkapasitas panjang garis bending $300 \mathrm{~mm}$, lebar bending $33 \mathrm{~mm}$, tinggi pegas $110 \mathrm{~mm}$, jarak langkah bebas $19 \mathrm{~mm}$. Sudut punch yang digunakan adalah $85 \square$ dengan radius punch yang digunakan yaitu $1,5 \mathrm{~mm}$ sedangkan sudut die yaitu $85 \square$. Material punch dan die yang dipilih yaitu Steel AISI 1045 HV HR.
\end{abstract}

Kata kunci : Bending V; Press tool; Punch; Dies

\section{PENDAHULUAN}

Dewasa ini proses pembentukan logam (metal forming) pada industri permesinan dan bengkel las berkembang sangat pesat khususnya pada proses tekuk. Proses tekuk merupakan pembentukan logam yang umumnya mengunakan lembaran pelat atau batang baik dari bahan logam ferro maupun logam non ferro dengan cara ditekuk, yang mana dalam proses tekuk akan menyebabkan terjadinya pemuluran atau peregangan pada sumbu bidang netral sepanjang daerah tekukan dan menghasilkan garis tekuk yang lurus. Fenomena perkembangan pembentukan logam melalui proses tekuk ini terjadi pada industri pabrikasi yang terdapat dikota-kota besar pada permesinan dan bengkel las baik yang berskala besar maupun berskala kecil pada daerah pedesaan. Hal tersebut dipicu oleh semakin banyaknya penggunaan berbagai macam teknologi mekanisasi khususnya dalam bidang ketahanan dan keamanan pangan dalam kehidupan masyarakat sehari-hari seperti teknologi proses pasca panen dan teknologi-teknologi mekanisasi pertanian lainnya. 
Beberapa proses tekuk yang sering dilakukan dalam proses manufaktur untuk pembuatan maupun perbaikan produk pada bengkel pabrikasi permesinan dan las seperti komponen panel elektronik, panel kendaraan mobil, tool box, pembakaran ikan, mesin dan alat mekanisasi pertanian dan sebagainya. Namun masih banyak bengkel-bengkel yang berskala kecil menekuk pelat dengan cara manual, yaitu menggunakan palu dan landasan besi sebagai alas sehingga waktu yang digunakan tidak efisien dan produk yang dihasilkan pun kurang terjamin kualitasnya. Peralatan yang dimiliki seuah industri biasanya mesin berkapsitas besar yang mana ongkos operasionalnya pun akan besar, sedangkan untuk memproduksi benda yang berukuran kecil tidak harus menggunkan mesin berkapasitas besar. Maka dari itu dibutuhkan alat tekuk pelat yang berukuran mini (kecil).

Dengan demikian diperlukan penerapan teknologi tepat guna untuk meningkatkan efektifitas pembentukan logam melalui proses tekuk ini. Penggunaan mesin-mesin berteknologi tepat guna telah banyak digunakan untuk meningkatkan produktivitas, efisiensi, dan efektivitas dalam proses produksi bagi usaha-usaha masyarakat khususnya yang ada di daerah. Salah satu teknologi tepat guna yang memungkinkan diterapkan dalam proses tekuk adalah mesin press yang dilengkapi dengan press tool.

Press tool adalah salah satu jenis alat bantu pembentukan, pemotongan dan penekukan produk dari bahan dasar lembaran pelat yang operasinya menggunakan mesin press. Berdasarkan proses pembentukannya Press tool diklarifikasikan menjadi tiga yaitu coining, bottoming dan air bending. Pembentukan dengan menggunakan coining dan bottoming memang lebih akurat tetapi untuk membutuhkan sudut bending yang berbeda, maka harus menggunakan punch dan die yang berbeda pula. Beda halnya dengan pembentukan logam menggunakan air bending, untuk mengasilkan sudut bending yang berbeda maka hanya perlu menggunakan satu punch dan die dan langkah penekanan yang berbeda.

\section{METODE PENELITIAN}

Penelitian ini dilaksanakan selama tiga bulan bengkel mekanik dan laboratorium mekanik Politeknik Negeri Ujung Pandang. Bahan-bahan yang digunakan dalam penelitian ini antara lain besi poros St 42, AS kotak St 42, dan pelat baja. Sedangkan peralatan yang digunakan adalah mesin frais, mesin bubut, mesin bor, mesin gerinda, mesin gergaji potong dan berbagai alat ukur dimensi. Beberapa tahap yang dilakukan dalam perancangan ini agar dapat berjalan dengan baik yaitu:

- Pertama yaitu tahap perancangan. Pada tahap perancanyan ini terlebih dahulu dilakukan perancangan konsep press tool bending $\mathrm{V}$ yang akan dibuat. Setelah hasil perancangan konsep selesai maka dilakukan pembuatan desain gambar sesuai dengan standar ISO. Desain gambar ini meliputi desain gambar rancangan secara keseluruhan dan desain gambar untuk semua komponen baik komponen yang dibuat maupun komponen standar.

- Kedua yaitu tahapan pembuatan dan perakitan. Pada tahap ini komponen-komponen yang tidak standar dilakukan pembuatan dengan mengacu pada gambar kerja hasil rancangan dan untuk komponen standar dibeli. Setelah semua komponen yang dibuat dan dibeli selesai maka dilakukan perakitan press tool berdasarkan hasil perancangan.

- Terakhir yaitu uji coba alat press tool air bending V brake. Pada tahap ini press tool yang telah dirakit selanjutnya diuji dengan melakukan pembendingan pelat dari baja karbon rendah. Proses uji coba dilakukan dengan menggunakan dies berbentuk V sudut $85^{\circ}$. Sedangkan punch yang digunakan bersudut $85^{\circ}$ dan radius $1.5 \mathrm{~mm}$. Setelah uji coba selesai maka produk yang dihasilkan selanjutnya diukur sudut bendingnya untuk mendapatkan. Bahan dasar lembaran yang digunakan yaitu pelat baja karbon St 37, ketebalan $3 \mathrm{~mm}$ dengan sifat mekanis sebagai berikut: 
50 Muhammad Arsyad Suyuti, Muhammad Iswar, Rusdi Nur, Erniyanti. Desain Konstruksi Press Tool Sebagai Alat Bending Bentuk V Dengan Garis Bending Max. 300mm

Tabel 1. Sifat mekanis material pelat baja karbon rendah ditekuk ketebalan $3 \mathrm{~mm}$

\begin{tabular}{|l|c|}
\hline \multicolumn{1}{|c|}{ Parameter Material } & Hasil Uji Tarik \\
\hline Kuat Tarik (MPa) & 389,333 \\
\hline Batas Ulur (N/mm $\left.{ }^{2}\right)$ & 322,667 \\
\hline Regangan (\%) & 31,25 \\
\hline Reduksi Penampang (\%) & 69,013 \\
\hline
\end{tabular}

\section{HASIL DAN PEMBAHASAN}

\section{A. Hasil Perancangan Press Tool}

Secara umum komponen utama press tool tediri dari die set, punch dan dies. Die set merupakan dudukan untuk merakit semua komponen press tool sehingga membentuk alat untuk memotong atau menekuk bahan dasar lembaran. Die set yang didesain akan digunakan sebagai alat bantu untuk melakukan pembengkokan material lembaran pelat dari baja karbon. Die set ini khusus dirancang agar punch dan diesnya dapat diganti-ganti sesuai dengan kebutuhan.

\section{B. Konsep Rancangan Konstruksi Press Tool}

Adapun hasil desain kontruksi alat bantu press tool untuk membending material lembaran pelat berbentuk V yang sudah dibuat terdiri dari tiga bagian utama yaitu die set, punch dan die. Hasil desain konstruksi press tool tersebut dapat dilihat pada gambar berikut ini:

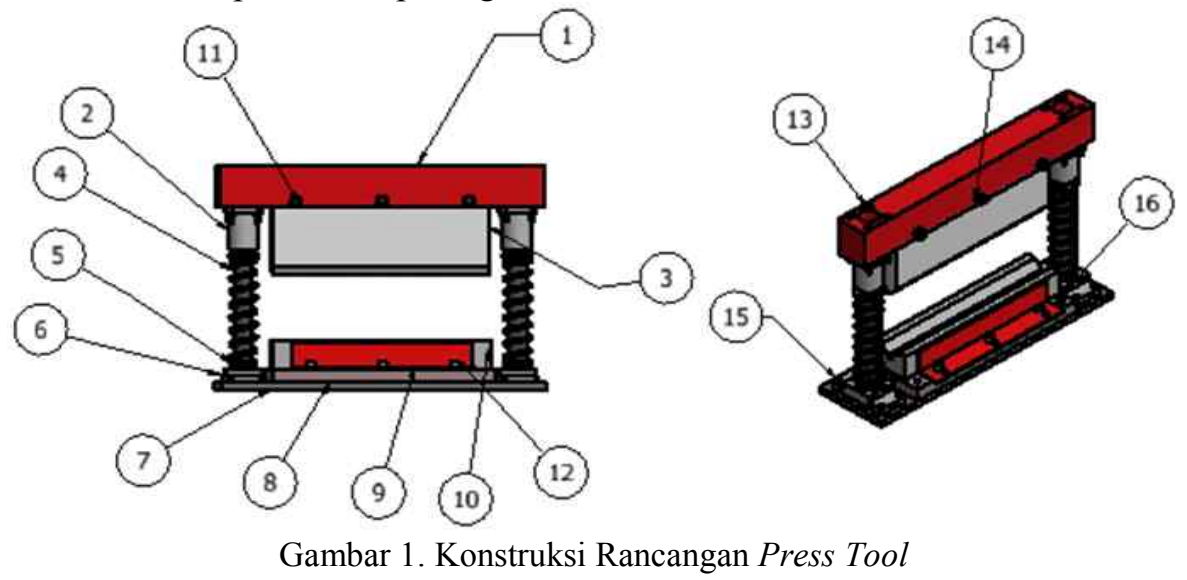

Pada gambar 1 diatas memperlihatkan bahwa desain konstruksi press tool yang dihasilkan terdiri dari 16 komponen antara lain: 1) Top plate; 2) Bearing; 3) Punch; 4) Pegas; 5) Poros; 6) Dudukan poros; 7) Bottom plate; 8) Pelat pelapis; 9) Pelat pengunci die; 10) Die; 11) Baut pengikat punch dan Top plate; 12) Baut pengunci die; 13) Baut bearing; 14) Mur pengikat punch;15) Baut dudukan; 16) Baut pelapis die.

\section{Perhitungan Konstruksi Press Tool}

Adapun hasil desain kontruksi alat bantu press tool untuk membending material lembaran pelat berbentuk $\mathrm{V}$ yang sudah dibuat terdiri dari tiga bagian utama yaitu die $s$

Dalam konsep rancangan pada gambar 1 terdapat beberapa komponen-komponen yang memiliki peran penting pada saat proses bending pelat berbentuk V dilakukan. Oleh karena itu diperlukan perhitungan kekuatan konstruksi dan pemilihan material yang tepat yang akan dipakai dalam pembuatan komponen. Berikut ini dilakukan beberapa perhitungan terhadap komponenkomponen yang dianggap kristis pada saat press tool bekerja:

\section{Menghitung beban komponen yang diangkat oleh pegas tekan}


Terdapat beberapa komponen die set yang membebani pegas dan harus diangkat kembali oleh pegas setelah punch selesai bekerja diantaranya pelat atas (top plate), punch, ring dan bearing. Untuk menentukan massa komponen alat bantu die set yang membebani pegas maka digunakan persamaan berikut ini:

$$
W=V \cdot \rho
$$

dimana: $\mathrm{W}=$ massa komponen $(\mathrm{kg}) ; \mathrm{V}=$ volume komponen $\left(\mathrm{mm}^{3}\right) ; \rho=$ massa jenis $\left(\mathrm{kg} / \mathrm{mm}^{3}\right)$

Bahan komponen top plat (pelat atas), punch, bearing, ring dan baut yang digunakan adalah bahan baja karbon dengan massa jenis $7860 \mathrm{~kg} / \mathrm{m}^{3}=0.00000786 \mathrm{~kg} / \mathrm{mm}^{3}$. Berikut ini perhitungan massa komponen-komponen yang memberi beban pegas:

\section{- Pelat atas (Top plate)}

Top pelat ini merupakan dudukan bagian atas punch yang terbuat dari material mild steel. Desain top plate dapat dilihat pada gambar berikut ini:
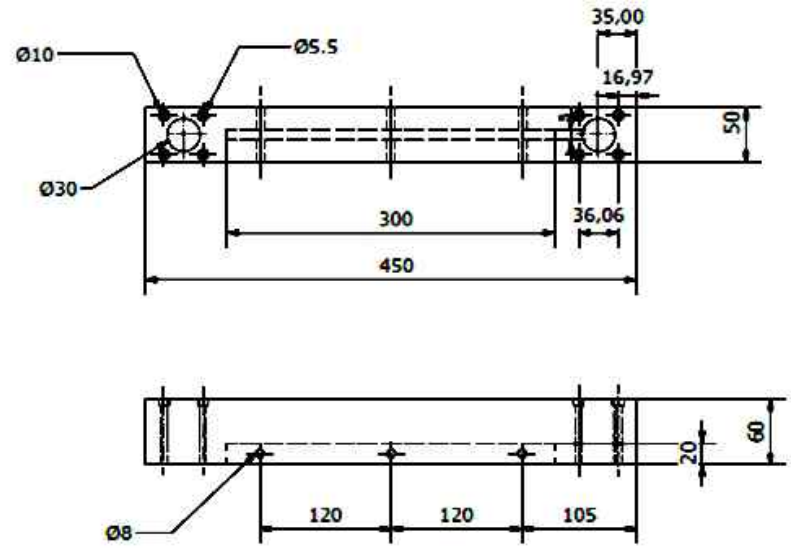

Gambar 2. Top plate

Berdasarkan gambar diatas, massa top plate dapat dihitung dengan volume bidang persegi $\left(\mathrm{V}_{\mathrm{I}}=\right.$ $\mathrm{p} \times 1 \times \mathrm{t})$ dikurang volume lubang baut $\left(\mathrm{V}_{\mathrm{II}}=\pi \mathrm{r}^{2} \mathrm{t}\right)$, volume lubang poros $\left(\mathrm{V}_{\mathrm{III}}=\pi \mathrm{r}^{2} \mathrm{t}\right)$ dan volume alur $\left(\mathrm{V}_{\mathrm{IV}}=\mathrm{p} \times 1 \times \mathrm{t}\right)$. Sehingga volume total $\left(\mathrm{V}_{\text {total }}\right)=\mathrm{V}_{\mathrm{I}}-\mathrm{V}_{\mathrm{II}}-\mathrm{V}_{\mathrm{III}}-\mathrm{V}_{\mathrm{IV}}=1.408 .960,8 \mathrm{~mm}^{3}$. Maka massa top plate $(\mathrm{W})=\mathrm{V} \times \rho=11,4076173 \mathrm{Kg}$

\section{- Punch}

Punch dalam desain ini merupakan komponen aktif yang berfungsi sebagai pembentuk atas (male) berbentuk $\mathrm{V}$ radius $1,5 \mathrm{~mm}$ dan dibuat dari material yang dapat dikeraskan jenis jenis Steel AISI 1045 HV. Adapun desain punch dapat dilihat pada gambar berikut ini:
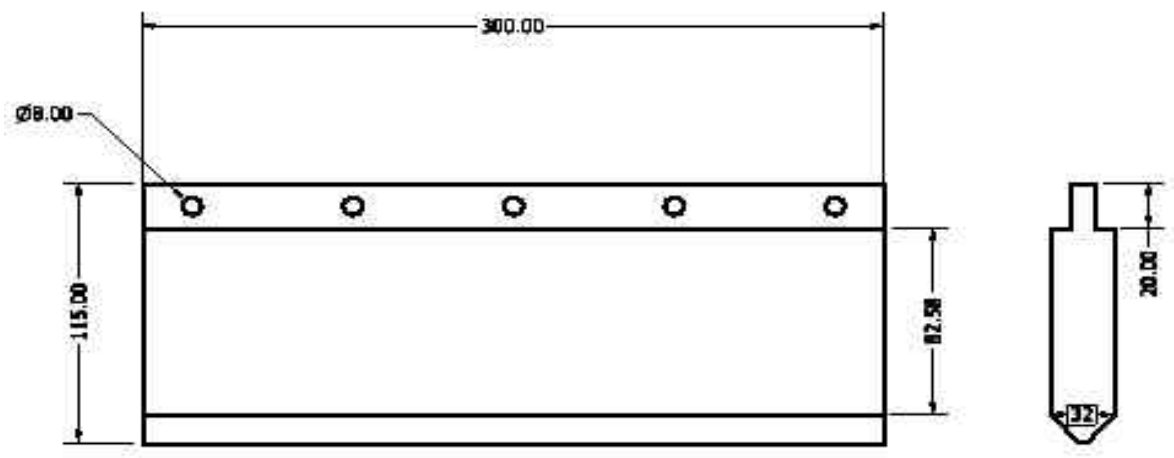

Gambar 3. Punch

Berdasarkan dimensi pada gambar di atas, maka volume punch dapat dihitung dengan mengurangi volume pada persegi punch $\left(\mathrm{V}_{\mathrm{I}}=\mathrm{p} \times 1 \times \mathrm{t}\right)=1.104 .000 \mathrm{~mm}^{3}$ dengan volume sejumlah lingkaran lubang $\left(\mathrm{V}_{\mathrm{II}}=\pi \mathrm{r}^{2} \mathrm{t}\right)=4.823,04 \mathrm{~mm}^{3}$, ditambah volume persegi $\left(\mathrm{V}_{\mathrm{III}}=\mathrm{p} \mathrm{x} 1 \mathrm{x}\right.$ $\mathrm{t})=792.768 \mathrm{~mm}^{3}$ dan volume segitiga $\left(\mathrm{V}_{\mathrm{IV}}=\mathrm{L}_{\mathrm{a}} \times \mathrm{t} \mathrm{V}_{\mathrm{IV}}\right)=59.616 \mathrm{~mm}^{3}$. sehingga total volume 
52 Muhammad Arsyad Suyuti, Muhammad Iswar, Rusdi Nur, Erniyanti. Desain Konstruksi Press Tool Sebagai Alat Bending Bentuk V Dengan Garis Bending Max. 300mm

punch adalah $\mathrm{V}_{\text {total }}=\mathrm{V}_{\mathrm{I}}-\mathrm{V}_{\mathrm{II}}+\mathrm{V}_{\mathrm{III}}+\mathrm{V}_{\mathrm{IV}}=1.951 .560,96 \mathrm{~mm}^{3}$. Maka besar massa punch $(\mathrm{W})=$ $15,339 \mathrm{~kg}$.

\section{- Bearing}

Bearing yang digunakan merupakan bearing standar yang terdapat dipasaran. Bearing berfungsi sebagai penepat tiang pengarah yang terpasang pada pelat atas dan terbuat dari material baja coran

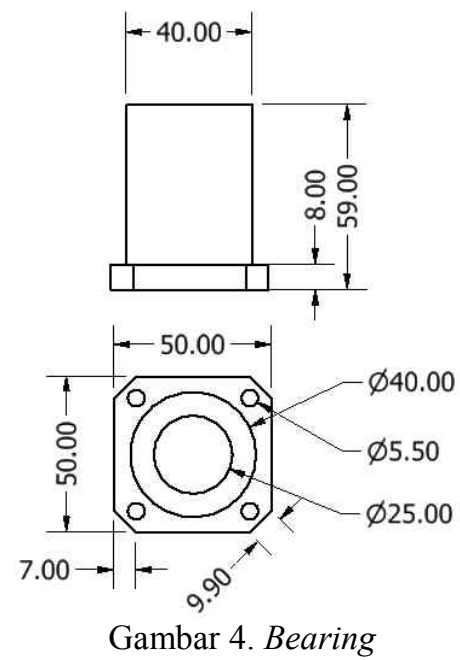

Untuk massa jenis bahan stainles steel adalah $7480 \mathrm{~kg} / \mathrm{m}^{3}$ atau $0.00000748 \mathrm{~kg} / \mathrm{mm}^{3}$, maka beban bearing $(\mathrm{W})=2,3770324 \mathrm{~kg}$.

\section{- Washer}

Washer yang digunakan adalah ring standar yang terbuat dari baja karbon terdapat dipasaran dengan dimensi diameter luar ring $40 \mathrm{~mm}$ dan diameter dalam $30 \mathrm{~mm}$ dengan tebal $2 \mathrm{~mm}$ dimana massa jenis bahannya $7860 \mathrm{~kg} / \mathrm{m}^{3}=0.00000786 \mathrm{~kg} / \mathrm{mm}^{3}$ sehingga berat $(\mathrm{W})$ sebesar $0.00123 \mathrm{~kg}$.

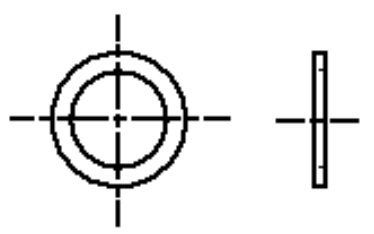

Gambar 5. Ring

Dari perhitungan beban komponen-komponen tersebut, maka total beban yang diterima oleh pegas adalah:

$$
\mathrm{W}_{\text {total }}=\mathrm{W}_{\text {top plate }}+\mathrm{W}_{\text {punch }}+\mathrm{W}_{\text {bearing }}+\mathrm{W}_{\text {ring }}=29,17 \mathrm{~kg}=291,7 \mathrm{~N}
$$

\section{Kekuatan beban oleh pegas}

Pegas yang digunakan harus mampu mengembalikan top plate pada saat proses bending telah selesai. Agar pegas yang dipilih dapat mengembalikan top plate pada posisi semula setelah pembebanan proses bending maka dalam pemilihan pegas perlu dihitung kekuatan pegas. Jika dipilih pegas dengan diameter pegas $40 \mathrm{~mm}$ dan diameter kawat $5 \mathrm{~mm}$, serta modulus geser $(\mathrm{G})=$ $83 \times 10^{3} \mathrm{~N} / \mathrm{mm}$. Maka besar beban yang mampu ditahan oleh pegas dapat dihitung dengan persamaan berikut ini (Dahlan, 2012): 


$$
W=\frac{\delta \cdot G \cdot d^{4}}{8 \cdot D^{3} \cdot n}
$$

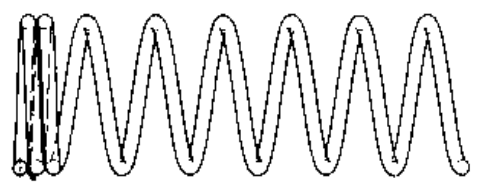

Gambar 6. Pegas

Berdasarkan gambar diatas, maka untuk menentukan beban pegas dilakukan perhitungan beban yang mampu ditahan oleh pegas sebagai berikut:

$$
\begin{aligned}
& W=\frac{\delta \cdot G \cdot d^{4}}{8 \cdot D^{3} \cdot n}=\frac{(L a-L i) \cdot G \cdot d^{4}}{8 \cdot D^{3} \cdot m} \\
& W=\frac{(110-100) \cdot 83 \times 10^{8} \cdot 5^{4}}{8 \cdot 40^{3} \cdot 2}=506,592 \mathrm{~N}
\end{aligned}
$$

Berdasarkan perhitungan teoritis di atas, maka sebuah pegas mampu menahan beban sebesar $506,592 \mathrm{~N}$.

Dengan demikian, bahwa dengan menggunakan 2 pegas pada die set maka beban yang mampu ditahan oleh pegas secara teoritis sebesar 1.013,184 N. Sehingga berdasarkan hasil perhitungan total beban komponen bagian atas die set yang diterima oleh pegas $\left(\mathrm{W}_{\mathrm{tot}}\right)$ sebesar 291,7 N maka spesifikasi pegas yang dipilih aman karena kemampuan menahan beban pegas lebih besar daripada total beban yang diterima.

\section{Gaya Tekuk Pelat}

Besarnya gaya maksimum yang dibutuhkan untuk menekuk pelat dengan tebal $3 \mathrm{~mm}$ dan panjang garis bending $300 \mathrm{~mm}$ dapat dihitung dengan menggunakan persamaan berikut ini (Suyuti, M. A.; 2015):

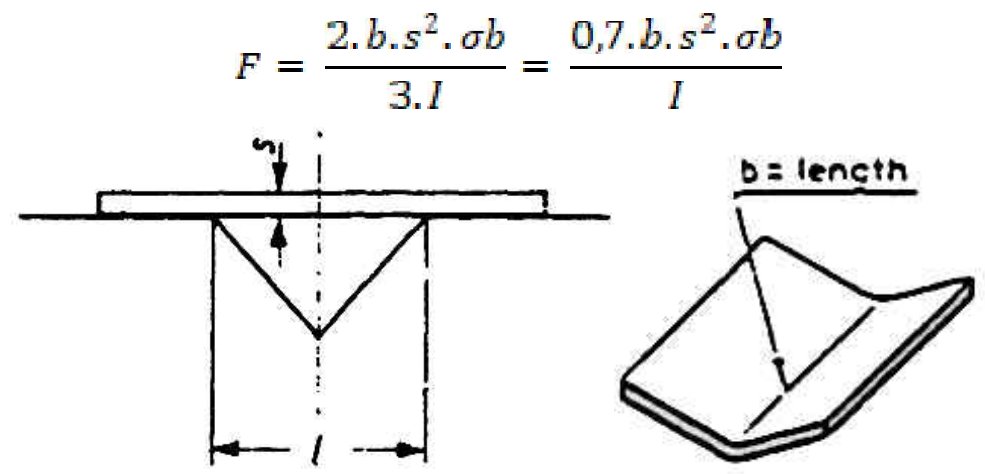

Gambar 7. Parameter Pelat yang akan Dibengkokkan

Material yang ditekuk adalah jenis baja karbon rendah dengan kekuatan tarik $\left(\sigma_{\mathrm{u}}\right)$ sebesar 389,333 $\mathrm{N} / \mathrm{mm}^{2}$. Dengan demikian tegangan bengkok dapat dihitung dengan rumus $\sigma_{\mathrm{b}}=0,8 \sigma \mathrm{t}=311,4664$ $\mathrm{N} / \mathrm{mm}^{2}$. Sehingga besarnya gaya bengkok yang digunakan dapat diperoleh sebagai berikut :

$$
\begin{aligned}
& F=\frac{0,7 \cdot b \cdot s^{2} \cdot \sigma b}{I} \\
& F=17.838,530 \mathrm{~N}
\end{aligned} \quad F=\frac{0,7 \times 300 \mathrm{~mm} x 3^{2} \times 311,4664 \mathrm{~N} / \mathrm{mm}^{2}}{33}
$$


54 Muhammad Arsyad Suyuti, Muhammad Iswar, Rusdi Nur, Erniyanti. Desain Konstruksi Press Tool Sebagai Alat Bending Bentuk V Dengan Garis Bending Max. 300mm

Dari hasi perhitungan tersebut diatas diperoleh besar gaya yang dibutuhkan pada pelat ketebalan 3 mm adalah $17.838,530 \mathrm{~N}$.

\section{Simulasi Material Punch dan die}

Dalam desain ini material punch dan die yang direkomendasikan yaitu baja karbon tinggi atau baja perkakas agar tahan gesekan dan deformasi. Sehingga pada desain punch dan die ini material yang dipilih adalah baja perkakas jenis Steel AISI 1045 HV HR dengan kuat tarik maksimum $\left(\sigma_{u}\right)$ sebesar $671 \mathrm{MPa}$, dimana material ini diharapkan tahan gesekan dan deformasi terhadap tekanan pada saat proses tekuk. Untuk memastikan kualitas mutu material Steel AISI 1045 HV HR ini dapat berfungsi dengan baik sebagai komponen punch dan die maka dilakukan simulasi static stress seperti berikut ini:

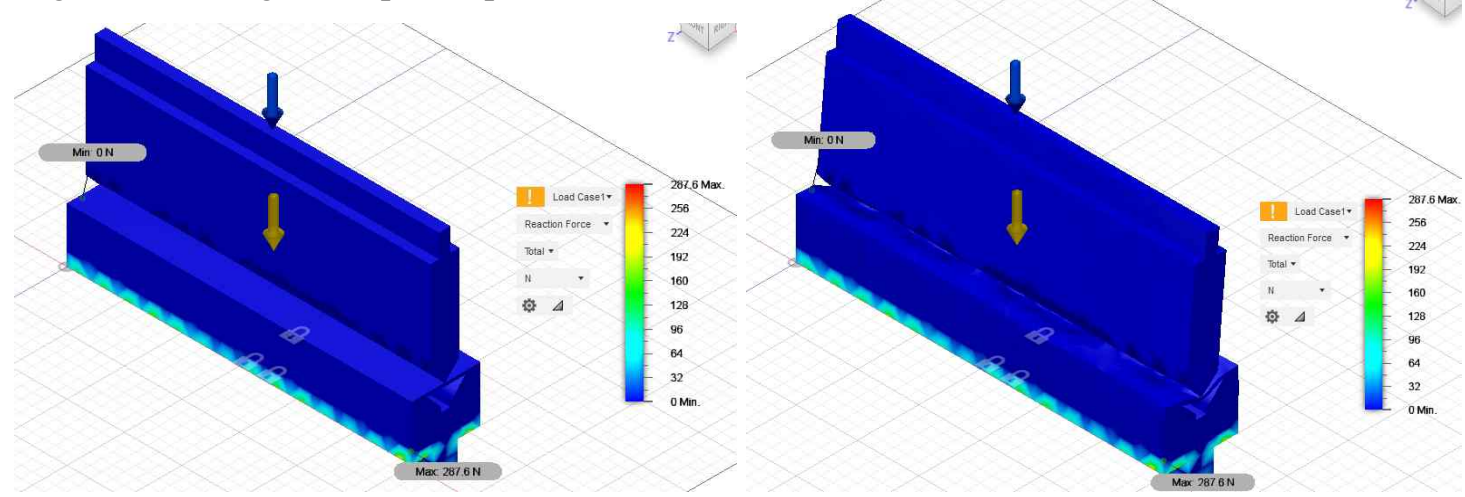

Gambar 8. Beban yang terjadi pada punch dan die setelah ditekuk dengan beban $17.800 \mathrm{~N}$

Berdasarkan hasil simulasi pada gambar 9. Diatas menunjukkan bahwa material die dan punch aman dari kerusakan akibat tekanan beban setelah menerima beban $17.800 \mathrm{~N}$, dimana hanya punch yang mendapat reaksi beban antara $0 \mathrm{~s} / \mathrm{d} 287 \mathrm{~N}$.
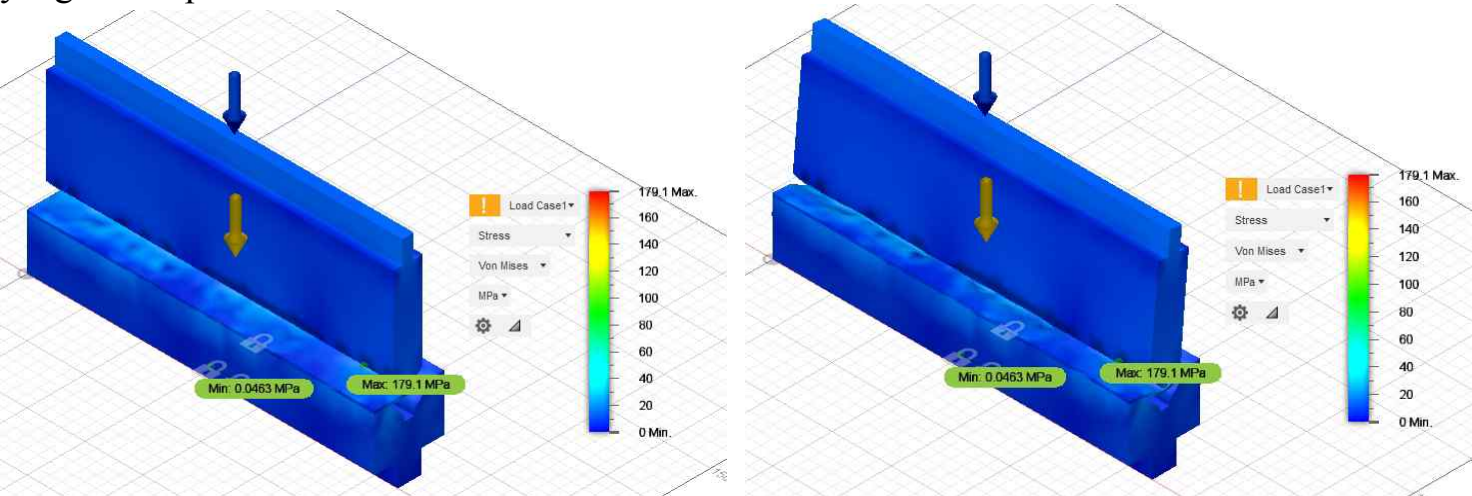

Gambar 9. Tegangan yang diterima oleh punch dan die setelah di tekuk dengan beban $17.800 \mathrm{~N}$

Berdasarkan hasil simulasi pada gambar 10. diatas menunjukkan bahwa material die dan punch menerima tegangan (stress) antara 0 s.d 179,1 MPa akibat tekanan beban sebesar $17.800 \mathrm{~N}$ yang diberikan. Sedangkan tensile stength material punch dan die (Steel AISI 1045) sebesar $671 \mathrm{MPa}$. Dengan demikian material punch dan die yang dipilih aman dari desakan tegangan akibat beban yang diterima. 


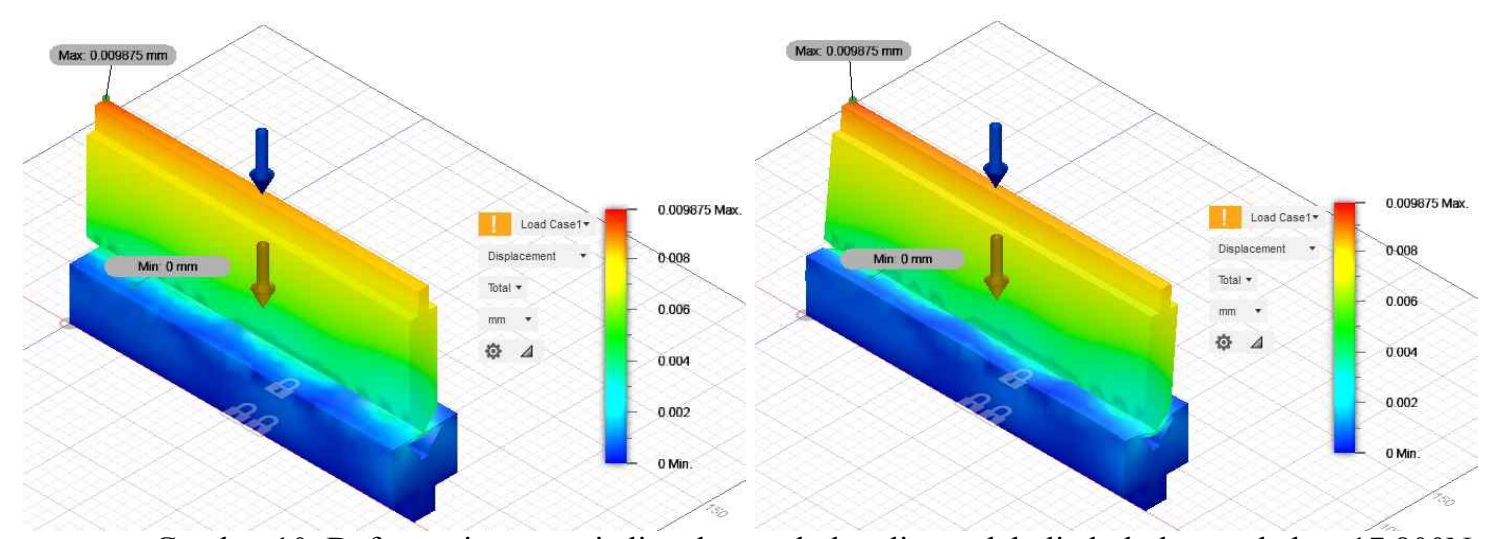

Gambar 10. Deformasi yang terjadi pada punch dan die setelah ditekuk dengan beban $17.800 \mathrm{~N}$

Sedangkan ditinjau dari segi deformasi yang terjadi pada saat menerima beban $17.800 \mathrm{~N}$ sebagai mana ditunjukkan pada hasil simulasi pada gambar 11. maka deformasi yang terjadi sangat kecil antara 0 s.d 0,009875. Sehingga punch dan die aman dari kerusakan akibat tekanan pada saat proses bending berjalan.

\section{KESIMPULAN}

Berdasarkan hasil desain dapat disimpulkan bahwa Press tool terdiri dari sub komponen utama yaitu die set, punch dan die. Spesifikasi press tool berkapasitas panjang garis bending $300 \mathrm{~mm}$, lebar bending $33 \mathrm{~mm}$, tinggi pegas $110 \mathrm{~mm}$, jarak langkah $19 \mathrm{~mm}$. Adapun dimensi pegas yaitu diameter pegas $40 \mathrm{~mm}$ dan diameter kawat $5 \mathrm{~mm}$. Dimensi punch memiliki punch $85^{\circ}$ dan radius $1,5 \mathrm{~mm}$ sedangkan sudut dies $85^{\circ}$. Material punch dan die yang dipilih yaitu Steel AISI 1045 HV HR.

\section{DAFTAR PUSTAKA}

[1] Carli. (2015). Analisis hasil pemotongan press tool pemotong strip plat pada mesin tekuk hidrolik promecam di laboratorium permesinan. Jurnal rekayasa. Vol 10 (3) : 86-90.

[2] Dahlan, Dahmir. (2012). Elemen Mesin. Jakarta: Citra Harta Prima.

[3] Erdin, Muhammed Emin dan Atmaca, Alper. (2016). Effects of Holding Force on the Springback Behavior of Annealed Aluminum Plates. International Conference on Manufacturing Engineering and Materials. Elsevier Procedia Engineering , Vol. $149: 56-61$

[4] Gautama, P., Ka'ka, S., Suyuti, M. A., \& Susanto, T. A. (2015). Desain Prototipe Alat Press Tool untuk Pembuatan O-Ring Sistem Pneumatik. Jurnal Teknik Mesin SINERGI, 12(2), 114-123.

[5] Kalpakjian, Serope dan Schmid, Steven R. (2010). Manufacturing Engineering and Technology, Edisi 6. Prentice Hall. New York-USA

[6] Kazan, Recep. (2008). Prediction of springback in wipe-bending process of sheet metal using neural network. Materials \& Design, Elsevier Journal Materials and Design, hal 418-423.

[7] Muhammad Reza dan Misbahuddin. 2014. Pengaruh Sudut Punch dan Ketebalan Pelat Terhadap Springback Pada Bending V. Tugas Akhir Jurusan Teknik Mesin Politeknik Negeri Ujung Pandang: Makassar.

[8] Nur, R., \& Suyuti, M. A. (2018). Perancangan Mesin-Mesin Industri. Deepublish.

[9] Suyuti, M. A., \& Nur, R. (2015). The Influence of Punch Angle on the Spring Back during VBending of Medium Carbon Steel. In Advanced Materials Research (Vol. 1125, pp. 157-160). Trans Tech Publications.

[10] Suyuti, M. A. (2015). Rancang Bangun Prototipe Alat Metal Forming Sirip Roda Besi Traktor Tangan. Jurnal Teknik Mesin SINERGI, 13(1), 62-74. 
56 Muhammad Arsyad Suyuti, Muhammad Iswar, Rusdi Nur, Erniyanti. Desain Konstruksi Press Tool Sebagai Alat Bending Bentuk V Dengan Garis Bending Max. 300mm

[11] Suyuti, M. A. (2015). Rancang Bangun Simpel Press Tool untuk Bending V Bottoming. Jurnal Teknik Mesin SINERGI, 13(2).

[12] Suyuti, M. A., \& Nur, R. (2017). The Effect of Embossing on the Rigidity of Wheel for Agricultural Tractors.

[13] Zulfikar, Muh. Abd. (2013). Rancang Bangun Alat Bending Pelat dengan Sistem Hidrolik. Tugas Akhir Jurusan Teknik Mesin Politeknik Negeri Ujung Pandang: Makassar. 